Document downloaded from:

http://hdl.handle.net/10251/49695

This paper must be cited as:

Giner Santonja, G.; Aragonés Beltrán, P.; Niclos Ferragut, JJ. (2012). The application of the analytic network process to the assessment of best available techniques. Journal of Cleaner Production. 25:86-95. doi:10.1016/j.jclepro.2011.12.012.

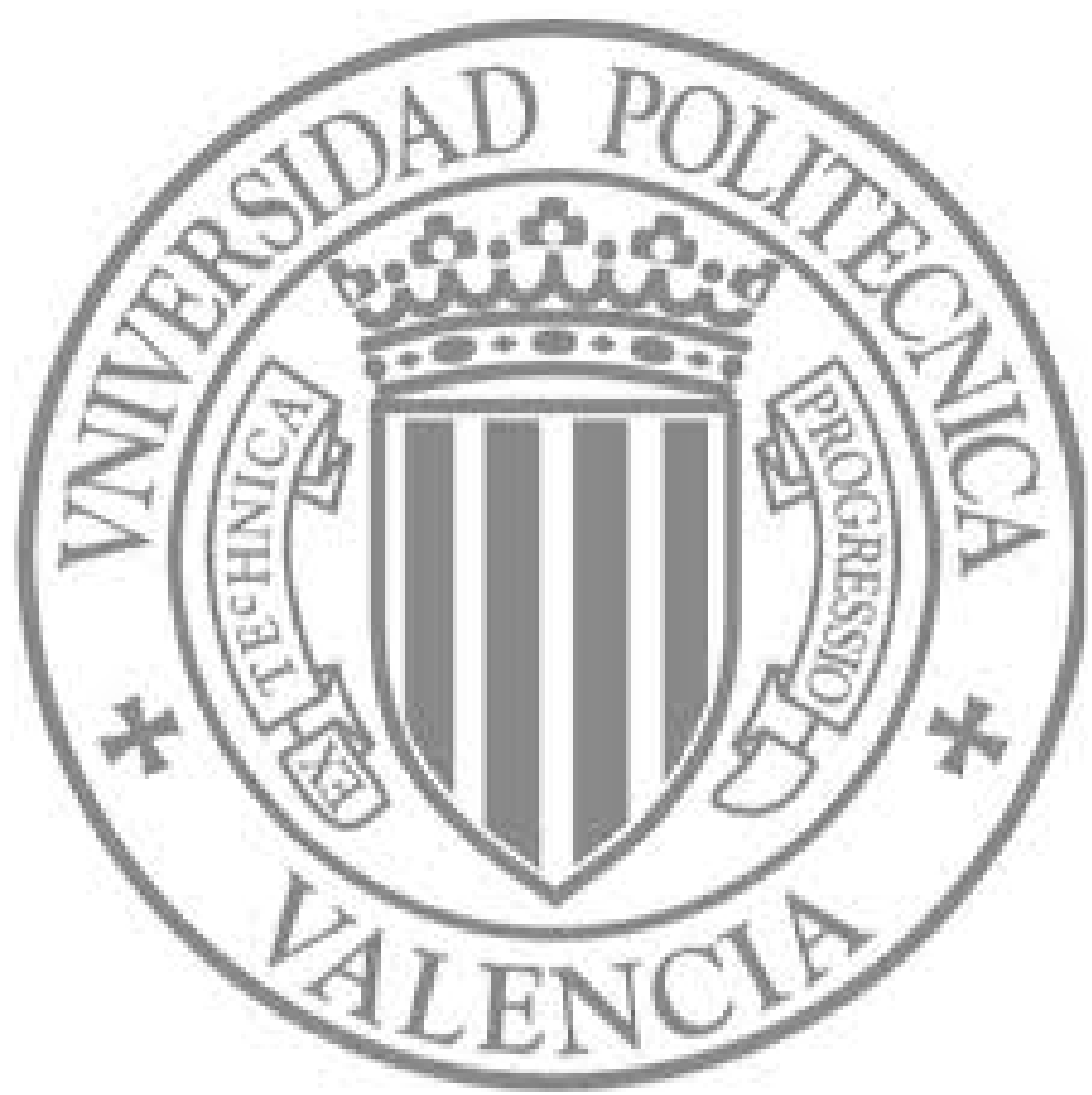

The final publication is available at

http://dx.doi.org/10.1016/j.jclepro.2011.12.012

Copyright Elsevier 


\title{
The application of the Analytic Network Process to the assessment of Best Available Techniques
}

\author{
Germán Giner-Santonja ${ }^{a^{*}}$, Pablo Aragonés-Beltrán ${ }^{\mathrm{b}}$, Joaquín Niclós-Ferragut ${ }^{\mathrm{c}}$
}

a: Clean Technologies Center. Department of Infrastructure, Planning and Environment Valencia Regional Government. Ronda Isaac Peral y Caballero 5. 46980 Paterna. Valencia. Spain.

b: INGENIO (CSIC-UPV), Universitat Politècnica de València, Camino de Vera s/n, 46022 Valencia, Spain.

c: Department of Engineering Projects. Universitat Politècnica de València, Camino de Vera s/n, 46022 Valencia, Spain.

*Corresponding Author. Tel. +34 961366949; fax: +34 961318495

Email addresses: giner_ger@gva.es (Giner-Santonja), aragones@dpi.upv.es (AragonésBeltrán), niclos_joa@gva.es (Niclós-Ferragut)

\begin{abstract}
The European Integrated Pollution Prevention and Control Bureau produces reference documents on Best Available Techniques, called BREFs. These documents give technical and descriptive information about the installations that represent a significant pollution potential in Europe. However, they do not provide an assessment of the Best Available Techniques, which is a decision to be made by the competent environmental authority. The present work proposes a decision making process for assessing Best Available Techniques based on the Analytic Network Process. Seven evaluation criteria, grouped into three clusters, have been proposed. The process is applied to a case study and the results are described and analyzed. As a main conclusion, this paper describes a robust and scientific method for a better implementation of the Integrated Pollution Prevention and Control approach.
\end{abstract}

Keywords: Best Available Techniques, BREF, ANP, IPPC 


\section{Introduction}

The real cause of the current financial crisis is the crisis of the industrial model based on intensive mass production and extensive use of cheap resources. This model, which was highly successful in the twentieth century, came to its end in the last decade. Today, ecoefficient innovation or eco-innovation has become a key concept in the EU (Jänicke, 2010).

One of the three priorities of the Europe 2020 Strategy (European Commission, 2010) is sustainable growth through the promotion of an economy that is greener, more competitive and more efficient in its use of resources. But to reach this goal substantial changes in the regulations are needed (Ashford \& Hall, 2011).

One of the most powerful tools for the promotion of eco-innovations is Directive 2008/1/EC concerning integrated pollution prevention and control (European Parliament, 2008), known as the Integrated Pollution Prevention and Control (IPPC) Directive. This Directive will be repealed on 7 January 2014 by Directive 2010/75/UE (European Parliament, 2010) on industrial emissions.

The IPPC Directive establishes a procedure for authorizing the activities listed in Annex 1 so that the owner of a new facility must request permission from the competent authority, which is then required to conduct an environmental assessment of the activity (EA-IPPC). The EAIPPC takes into consideration all factors involved in the activity: characteristics of the installation, industrial processes, impact of pollutants on water, soil, air and workers health. The results of the EA-IPPC serve to write a report specifying the operational requirements of the activity. This report is called the Integrated Environmental Authorization (IEA) and should comply with the IPPC regulations. The IPPC approach considers the establishment of emission limit values based on Best Available Techniques (BAT) but is does not prescribe the use of any technique or specific technology, or take into account the technical characteristics of the installation concerned, its geographical location and local environmental conditions

According to the IPPC Directive, BAT means the most effective and advanced stage in the development of activities and their methods of operation which indicates the practical suitability of particular techniques for providing in principle the basis for emission limit values designed to prevent and, where that is not practicable, generally to reduce emissions and the impact on the environment as a whole.

For the correct implementation of the IPPC approach the competent authority should know and assess all existing BAT before conducting the IEA of an IPPC installation. Similarly, the holder of the facility should include the most suitable BAT in his application form. However, the use of BAT is not restricted to the scope of the IPPC Directive, but any company can implement a BAT in its production process as a tool to improve eco-efficiency and consequently competitiveness. This is because the IPPC approach prioritizes pollution prevention over treatment (Honkasalo et al., 2005).

The European Commission, through the European IPPC Bureau, publishes reference documents for different IPPC sectors (mainly industrial and farming) that contain a description of the main processes, environmental aspects and associated list of BAT. These documents, called Reference Documents on Best Available Techniques (BREF) are publicly available and provide technical details and general descriptive information, but do not include an assessment of these techniques, which is a key issue for the correct implementation of the IPPC approach.

The implementation of BAT generally involves the installation of new equipment or machinery. The correct selection of a BAT is an important decision for a company, especially if it is located in an environmentally sensitive area (Samarakoon and Gudmestad, 2011). Using the right equipment can improve the production process, facilitate the efficient use of 
labor, increase productivity and improve flexibility. The selection of new equipment can become a long and difficult process, requiring sound knowledge and extended experience. For proper and effective evaluation of the alternatives, decision-makers have to analyze a large amount of data and consider various quantitative and qualitative criteria. In other words, it is a multicriteria decision making (MCDM) problem (Ayag and Ozdemir, 2006).

The Life Cycle Assessment (LCA) approach seems to be the most environmentally suitable technique to compare different types of equipment because it determines the environmental impacts associated with resource use and pollutant discharges to the environment. LCA application is regulated by ISO 14.040:2006, though it is difficult to find accurate data on the characteristics and potential impacts of the machinery under evaluation. This is another important pitfall hindering the correct implementation of the IPPC Directive (Bréchet and Tulkens, 2009).

A different approach for the evaluation of BAT is based on Multi-Criteria Decision Analysis (MCDA). Belton and Stewart (2002) define MCDA as a term that includes a set of concepts, methods and techniques that seek to help individuals or groups to make decisions, which involve several points of view in conflict and multiple stakeholders. All these MCDA concepts and methods have been largely studied in the Operational Research literature (Belton and Stewart, 2002), (Pomerol and Barba-Romero, 2000) (Figueira et al., 2005).

In this work the Analytic Network Process (ANP) proposed by Saaty (2001) as a generalization of the Analytic Hierarchy Process (AHP) (Saaty, 1980) is used to evaluate BAT. The ANP process starts with the formulation of the problem and ends with a comparison of the results obtained from both techniques.

MCDA techniques have been used for technology assessment: Doukas et al. (2006) used PROMETHEE II to assess technologies for power generation, Bollinger and Pictet (2008) used ELECTRE III to evaluate waste incineration technologies, Gómez-Lopez et al. (2009) used TOPSIS to assess disinfection technologies for wastewater reuse.

However, there are few studies that apply MCDA techniques to the evaluation of BAT. Dijkmans (2000) selected BAT for two IPPC activities through qualitative assessment based on BAT availability in the market, environmental impacts and economic feasibility. Schultmann et al. (2001) compared different BAT from an economic viewpoint by estimating the costs associated with initial investment and maintenance. Geldermann and Rentz (2001) used PROMETHEE for the evaluation of BAT that can reduce atmospheric emissions, especially when using uncertain data. These authors proposed the reference installation approach in 2004, which consists of assigning a class type to the IPPC installation under evaluation, so that the same emission measures (BAT) are applied to all facilities belonging to the same IPPC category. In their work the authors also used AHP (Geldermann and Rentz, 2004). Georgopoulou et al. (2008) developed a software tool for BAT assessment called BAT Economic Attractiveness Tool. The tool performs a quantitative analysis of the economic and environmental effects resulting from the implementation of a BAT. Barros et al. (2008) identified and analyzed the potential BAT for a fish farm from different published BREF and their experience in the sector in Galicia, and selected those BAT that could improve environmental performance. Liu and Wen (2012) selected BAT using Data Envelopment Analysis, for the case of thermal power plants in China.

\section{Overview of AHPIANP}

The Analytic Hierarchy Process (AHP) and the Analytic Network Process (ANP) are two methods proposed by Saaty (Saaty, 1980, 1996a, 2001, 2005, 2008). AHP is a well-known 
technique based on the fact that the inherent complexity of a multiple criteria decision making problem can be modeled breaking down it into several levels in such a way that they form a hierarchy with unidirectional hierarchical relationships between levels. The top level of the hierarchy is the main goal of the decision problem. The lower levels are the tangible and/or intangible criteria and subcriteria that contribute to the goal. The bottom level is formed by the alternatives to evaluate in terms of the criteria. In each hierarchical level paired comparisons are made with judgments using numerical values taken from the AHP absolute fundamental scale of 1-9. These comparisons lead to dominance matrices from which ratio scales are derived in the form of principal eigenvectors. These matrices are positive and reciprocal (aij $=1 / a j i)$. The synthesis of AHP combines multidimensional scales of measurement into a single one-dimensional scale of priorities. The method also calculates a consistency ratio (CR) to verify the coherence of the judgments, which must be about 0.10 or less to be acceptable. Mathematical foundations of AHP can be found in Saaty (1994, 1996b).

AHP is conceptually easy to use; however its strict hierarchical structure cannot address the complexities of many real-world problems. As a solution, Saaty proposed the ANP model, a generalization of AHP. ANP represents a decision-making problem as a network of criteria and alternatives (all called elements), grouped into clusters. All the elements in the network can be related in any possible way, i.e. a network can incorporate feedback and complex inter-relationships within and between clusters. This provides a more accurate modeling of complex settings. The influence of the elements in the network on other elements in that network can be represented with a supermatrix. This new concept consists of a twodimensional element-by-element matrix which adjusts the relative importance weights in individual pairwise comparison matrices to build a new overall supermatrix with the eigenvectors of the adjusted relative importance weights. According to Saaty (2001), the ANP model comprises the following steps:

(i) Identifying the components and elements of the network and their relationships.

(ii) Conducting pairwise comparisons on the elements.

(iii) Placing the resulting relative importance weights (eigenvectors) in pairwise comparison matrices within the supermatrix (unweighted supermatrix).

(iv) Conducting pairwise comparisons on the clusters.

(v) Weighting the blocks of the unweighted supermatrix, by the corresponding priorities of the clusters, so that it can be column-stochastic (weighted supermatrix).

(vi) Raising the weighted supermatrix to limiting powers until the weights converge and remain stable (limit supermatrix).

Other authors have used the AHP method for the assessment of different technologies. Tabucanon et al. (1994) used AHP for the selection of machines in flexible manufacturing systems. Prabhu and Vizayakumar (1996) used AHP to select technologies through technical, socio-economic and environmental criteria. Chan et al. (2001), Cziner et al. (2005) and Gerdsri and Kocaoglu (2007) used AHP to integrate new industrial equipment in the production process by various criteria: economic costs, technological efficiency, safety, environmental factors, and so on. Chowdhury and Husain (2006) used AHP in combination with the fuzzy set theory for evaluation of drinking water treatment technology. Remanufacturing of technologies has been assessed using AHP in recent studies (Subramoniam et al., 2011; Du et al., 2012, Jiang et al., 2011).

ANP has also been used in environmental works. For example, Erdoğmuş et al. (2006) used ANP to select the optimal type of fuel for residential heating in Turkey, Ulutas (2005) and Dağdeviren and Eraslan (2008) used ANP to prioritize energy policies in Turkey, Köne and 
Büke (2007) used ANP to evaluate fuels for electricity generation, Bathe et al. (2007) evaluated potential locations for a landfill, Aragonés-Beltrán et al. (2010) to locate municipal solid waste treatment plants, Gómez-Navarro et al (2009) to propose an index of environmental pressure for urban development planning, Yüksel and Dağdeviren (2007) to select technologies in a textile industry. However, no ANP applications were found in the literature that evaluate BAT

The reasons for using an ANP-based decision analysis approach in the present work are: (i) the assessment of BAT is a multicriteria decision problem; (ii) there are dependencies among groups of criteria and between these and the alternative techniques under evaluation; (iii) the detailed analysis of the inter-relationships between clusters forces the decision makers to carefully reflect on their project priority approach and on the decision-making problem itself and helps DMs to gain a better understanding of the problem and to make a more reliable final decision, (iv) the model permits the consideration of qualitative and quantitative criteria, v) the model also takes into consideration the opinions of a multidisciplinary team.

Its main drawback is the difficulty in modeling influences among the elements involved in the evaluation process. In complex models the questionnaires generally contain simple questions but there are too many, which may cause tiredness and boredom in the decisionmaker. Subnets and BOCR analysis (Benefits, Opportunities, Costs and Risks) can be used instead.

Another problem may arise when the number of alternatives to be assessed is very high (more than 7) or they are heterogeneous. In this case, Saaty suggests applying ratings evaluation or grouping alternatives into homogeneous groups (Saaty and Shang, 2011).

\section{The BAT assessment process and the ANP modeling approach}

The BAT assessment method proposed in this work is shown in Figure 1. The experts of the competent authority act as Decision Maker (DM) as specified in the IPPC Directive. These experts are a multidisciplinary team consisting of lawyers, engineers, biologists, chemists and environmental technicians, who are specialized in different areas related to industrial activity and its impact on the environment. 


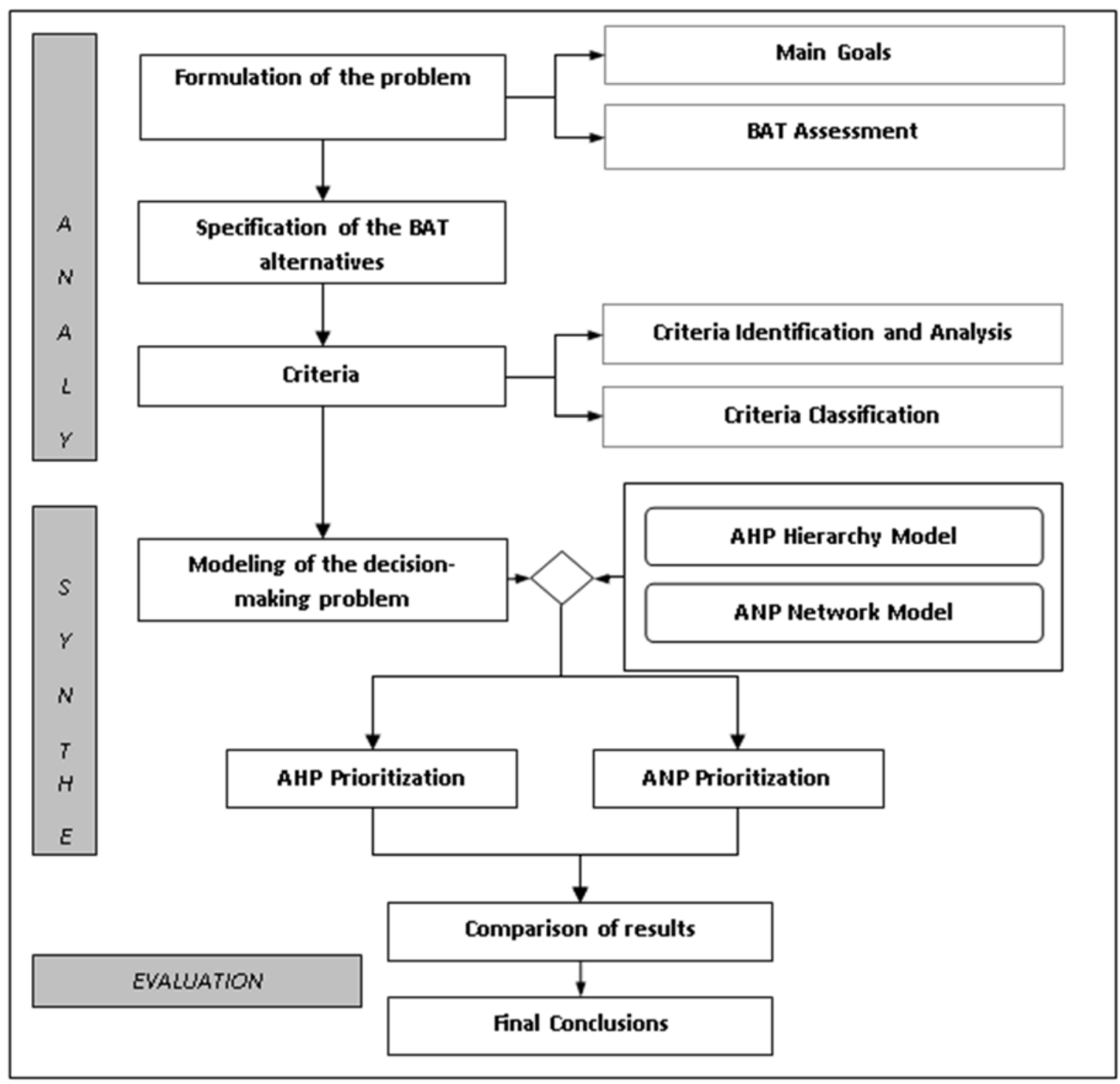

Figure 1: BAT assessment model (adapted from Aragonés-Beltrán et al., 2010b)

\subsection{Phase of problem analysis}

The starting point for the selection of a BAT are the BREF documents, as well as the national guidelines and, occasionally, local guidelines. These documents are prepared and updated by multidisciplinary working groups, composed of personnel from the competent authorities, representatives of the productive sector, technology centers, professional associations and environmentalists. From a methodological point of view, these working groups are considered as a decision group with different views, so that these documents do not contain a BAT assessment.

BREF design is an iterative process that involves the following steps:

- Identification of the key environmental aspects of the productive sector.

- Analysis of the BAT techniques that act on these key issues, including costs, resource use and associated environmental impacts.

- Identification of best environmental performance, according to information available in the European Union and worldwide. 
- Selection of a BAT in accordance with Annex IV of the IPPC Directive, including a description of its environmental advantages

The BREFs reflect the overall environmental situation of a given industrial sector but cannot analyze each individual facility (Schoenberger, 2009). Therefore, these documents only include a list of BATs for each stage of the production process.

The formulation of the problem under analysis in this paper is: "Given a particular facility for which the holder requests the IEA, the competent authority should evaluate the BAT for each environmental aspect in the available BREF documents before issuing the corresponding authorization."

The alternatives to evaluate will be selected by the DM based on the BREFs and his professional experience. These are the considerations to be taken into account generally or in specific cases when determining best available techniques, as defined in Annex IV of the IPPC Directive:

- the use of low-waste technology;

- the use of less hazardous substances;

- the furthering of recovery and recycling of substances generated and used in the process and of waste, where appropriate;

- comparable processes, facilities or methods of operation which have been tried with success on an industrial scale;

- technological advances and changes in scientific knowledge and understanding;

- the nature, effects and volume of the emissions concerned;

- the commissioning dates for new or existing installations;

- the length of time needed to introduce the best available technique;

- the consumption and nature of raw materials (including water) used in the process and energy efficiency;

- the need to prevent or reduce to a minimum the overall impact of the emissions on the environment and the risks to it;

- the need to prevent accidents and to minimize the consequences for the environment;

- the information published by the Commission pursuant to Article 17(2), second subparagraph, or by international organizations.

Based on these criteria and the scientific literature, this paper proposes seven evaluation criteria, grouped into three clusters:

Cluster 1: Economic Criteria.

- C11 Implementation costs: they are basically the costs of implementation of BAT, i.e. the investment and engineering costs as well as the implementation costs (Cziner et al., 2005).

- C12 Resource Consumption: these criteria refer to the operation and maintenance of BAT, the inputs needed for daily operation (water, electricity, raw materials, reagents, etc.) (Barros et al., 2009).

- C13 Energy efficiency: these criteria take into account the BAT power efficiency, which in turn affects productivity (Honkasalo et al., 2005).

Cluster 2: Environmental Criteria.

- C21 Wastewater management: they refer to the quantity and quality of generated wastewater, and its management (Geldermann and Rentz, 2004).

- C22 Air Emissions Management: criteria related to the nature and quantity of air emissions, and their impact on the environment (Georgopoulou et al., 2008). 
- C23 Waste management: aspects associated with the amount and type of waste generated and its management according to the waste management hierarchy (Djikmans, 2000).

Cluster 3: Social criteria (Gómez-López et al., 2009).

- C31 Workers Health: This cluster includes the degree of influence of the BAT on the health of the workers working in the plant. It also includes the possible effects on the people living near the IPPC installation. Mathematical models of dispersion of pollutants should be used to determine the distance thresholds.

This structure is applicable to any BAT assessment analysis.

\subsection{Phase of data synthesis}

In this phase the decision model is specified. For this purpose in the present work the AHP and ANP methods are used following two main decision analysis models: one hierarchy model and another network-based model. Following is a description of both decision analysis models.

\subsubsection{The hierarchy model}

The hierarchy model is as follows:

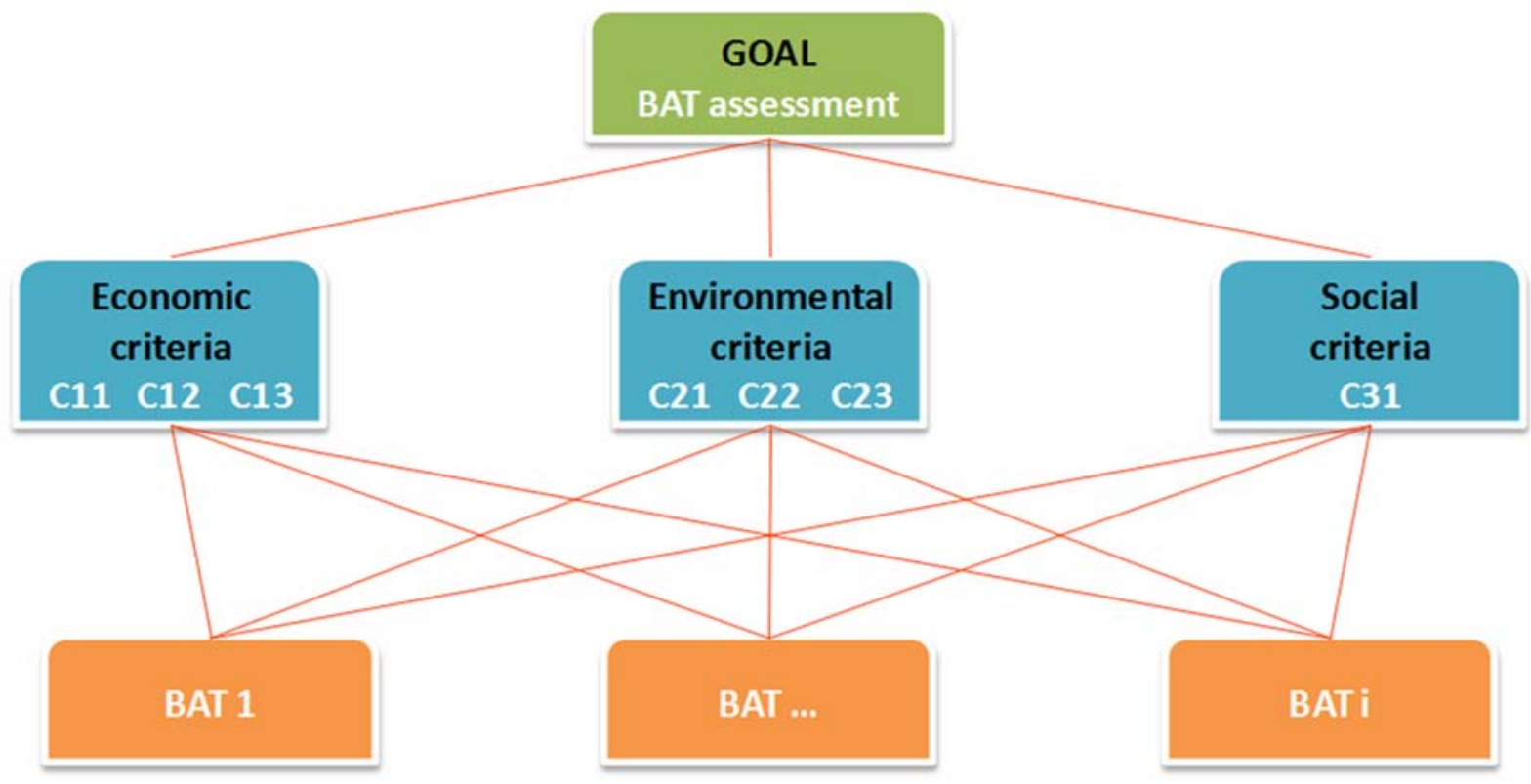

Figure 2. AHP-based Hierarchy model for BAT assessment

In this model, we have identified three sets of criteria (higher-level criteria), each of which includes elements or bottom-level criteria. First the weights of the criteria were set and subsequently the value of each alternative was calculated with respect to each criterion. According to AHP in the case study the criteria weights were obtained by pairwise comparison and represented the importance that the DM assigned to each of them.

\subsubsection{The network model}

The alternatives (BAT) were then evaluated with this model taking into account the influences between the elements of the problem (criteria and alternatives). The values 
obtained indicate the influence of each element on the whole system. This is a more complex model because it requires the DM to thoroughly analyze the problem.

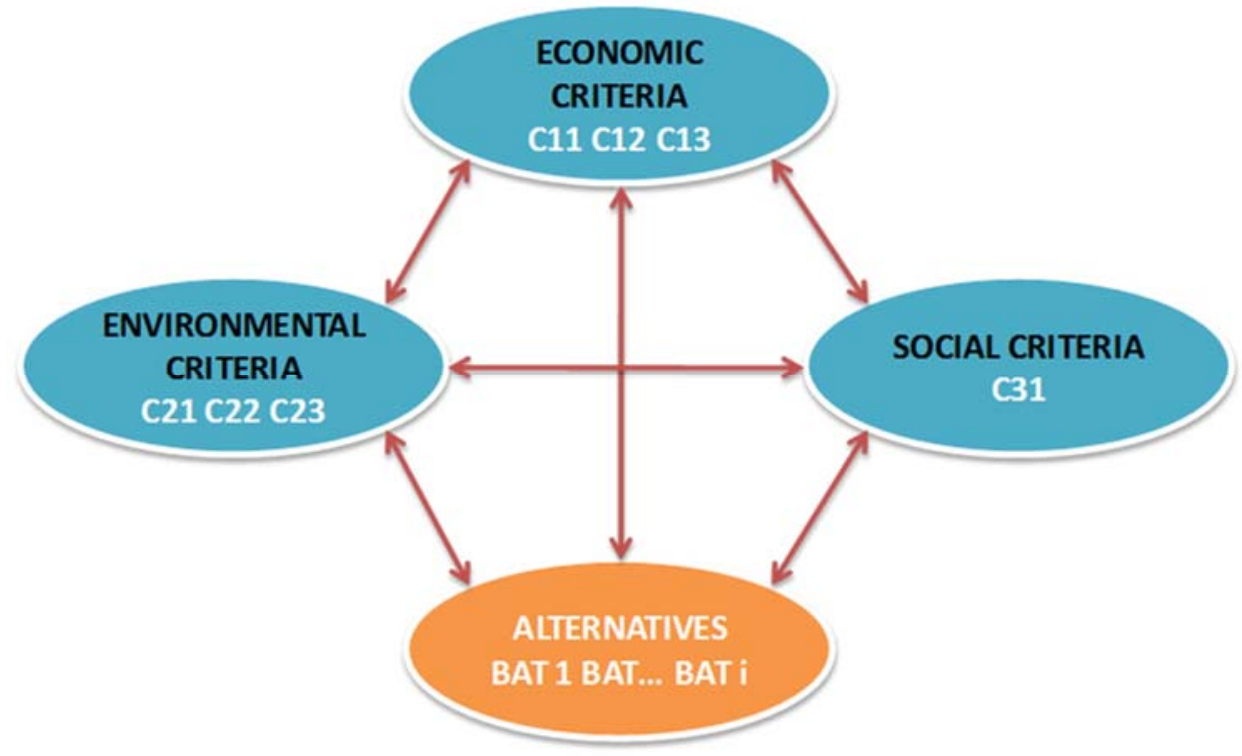

Figure 3: ANP-based Network model for BAT assessment

\section{Case study}

\subsection{Analysis.}

The aim of the case study is: "evaluation of the best available techniques to control the emission of particles into the atmosphere from powder processing in a tile industry in the province of Castellón (Spain)."

A multidisciplinary team was formed consisting of six technicians of the Clean Technologies Center of Valencia, part of the Department of Infrastructure, Planning and Environment (Valencia Regional Government). The members of the team have long experience in drafting regional BAT documents, and acted as Decision Maker (DM) in the decision process. The DM was assisted by a researcher of the Department of Engineering Projects of the Polytechnic University of Valencia, who acted as Analysis Team (AT). The DM used the consensus criteria outlined in the previous section.

From the BAT reference documents for the ceramic tile industry in Valencia (Spain) (Instituto de Tecnología Cerámica y Comisión de Trabajo, 2009) the DM selected the three BAT that he considered to be the most suitable for the facility under analysis.

- BAT 1: Covering the conveyor belts that manage dusty materials.

- BAT 2: filtering the air resulting from sucking in the load and dispensing of raw materials.

- BAT 3: using pneumatic conveying systems.

In addition to the particular requirements of these BAT, the DM also had to take into consideration their relevance to the technical and environmental characteristics of the IPPC installation. 


\subsection{Synthesis}

\subsubsection{Hierarchy Model}

Following AHP, once the hierarchy is established, the process follows three steps: i) criteria weighting, ii) evaluation of BAT for each criterion, and iii) results and findings. The first two steps are based on individual pairwise comparison matrices for the different levels and sublevels. In the step i) the eigenvector of each matrix gives the local weight of the criteria at each level and sublevel. This weight represents the importance that the DM assigns to each criterion in comparison to the other criteria in the same level. The global weight corresponding to each criterion is obtained multiplying its local weight by the global weight corresponding to the criterion from the next higher level. These global weights of criteria represent the importance that the DM assigned to each of them in comparison to all criteria of the model.

The individual judgements emitted by each DM were aggregated using the geometric mean (Saaty and Peniwaty, 2008). In order for the DMs to give their judgments on each matrix, a questionnaire was designed with the following question: Given a certain higher-level control criterion (e.g. economical, environmental or social) and two lower-level criteria, Which criterion is more important and to what extent according to Saaty's 1-9 scale?. Next, another questionnaire was designed to evaluate the different alternatives based on their relative criteria levels using questions such as: Given a certain criterion and two alternatives to compare, which alternative better satisfies the criterion and to what extent according to Saaty's 1-9 scale?. In all individual judgement matrices it was verified that their consistency ratios were less than 0.1

Table 1 shows the local and global (aggregated) weights of the criteria, according to the hierarchy approach.

\begin{tabular}{|c|c|c|c|c|}
\hline GOAL & CLUSTER & CRITERIA & Local & Global \\
\hline \multirow{7}{*}{$\begin{array}{c}\text { BAT } \\
\text { assessment }\end{array}$} & \multirow{3}{*}{$\begin{array}{c}\text { ECONOMIC } \\
\text { CRITERIA } \\
0.741\end{array}$} & C11. Implementation costs & 0.193 & 0.143 \\
\hline & & C12. Resource consumption & 0.268 & 0.199 \\
\hline & & C13. Energy efficiency & 0.540 & 0.400 \\
\hline & \multirow{3}{*}{$\begin{array}{c}\text { ENVIRONMENTAL } \\
\text { CRITERIA } \\
0.184\end{array}$} & C21. Wastewater management & 0.319 & 0.059 \\
\hline & & C22. Air emissions management & 0.391 & 0.072 \\
\hline & & C23. Waste management & 0.291 & 0.054 \\
\hline & $\begin{array}{c}\text { SOCIAL CRITERIA } \\
0.074\end{array}$ & C31. Workers health & 1 & 0.074 \\
\hline
\end{tabular}

Table 1 Local and global weights of the criteria

The criteria rated highest by the DM were energy efficiency $(\mathrm{C} 13)$ and resource consumption (C12).

Then each member of the DM was asked to assess the BAT for each criterion. When setting individual preferences by means of pairwise comparisons between BAT, it was taken into account that the highest rated BAT were those involving less consumption of resources, lower economic cost, less impact on water, air and workers health, and greater energy efficiency and better waste management. Table 2 shows the scores obtained and the final priority, calculated according to AHP. The higher the score the better the alternative 


\begin{tabular}{|c|c|c|c|c|c|c|c|c|}
\hline $\begin{array}{l}\text { GLOBAL } \\
\text { WEIGHTS }\end{array}$ & $\begin{array}{c}\text { C11 } \\
0.142\end{array}$ & 0.199 & 0.400 & 0.059 & 0.072 & 0.054 & $\begin{array}{c}\text { C31 } \\
0.074\end{array}$ & $\begin{array}{c}\text { Final } \\
\text { Priority }\end{array}$ \\
\hline BAT 1 & 0.73 & 0.69 & 0.28 & 0.44 & 0.16 & 0.29 & 0.29 & 0.430 \\
\hline BAT 2 & 0.18 & 0.19 & 0.05 & 0.20 & 0.07 & 0.07 & 0.07 & 0.112 \\
\hline BAT 3 & 0.09 & 0.11 & 0.66 & 0.36 & 0.77 & 0.63 & 0.63 & 0.458 \\
\hline
\end{tabular}

Table 2: AHP priority matrix for particulate emissions

The DM's suggestion was to implement BAT 3, use of pneumatic conveying systems.

\subsubsection{Network Model}

4.2.2.1 Determination of the network. This step requires the DM to have a good understanding of the problem using the advice given by the AT based on the data gathered in previous stages. The steps needed for the construction of the network are: i) determination of the elements, ii) determination of the clusters, and iii) determination of the influence network. The first two steps of identification and clustering of criteria have been described in the section Problem Analysis.

For the determination of the influences between the elements of the network a zero-one interfactorial dominance matrix was used (Saaty 2001) whose elements $a_{i j}$ take the value 1 or 0 depending on whether there is or there is not some influence of element $\mathrm{i}$ on element $\mathrm{j}$. The rows and columns of the matrix are formed by all the elements of the network.

In ANP, the numerical data can be represented graphically and thus show the influence pattern of the network. This step is essential for further development of the process because if all the complexity of the real-world case study is to be transferred to the model, the DM has to accurately identify the influences of some elements upon others based on his knowledge and experience. If the DM fails to identify one influence, the model will not take it into account and some valuable information will be lost (Aragonés-Beltrán et al., 2010). For this reason the DM was asked to identify these influences, which are shown in Table 3.

The DM made the following assumptions for the case study under analysis: i) there are no influences among the different BAT due to the fast advance of environmental technology. This implies the assumption that the BAT will always be different and independent and, therefore, there will be no influence on each other; ii) there are no influences among criteria of the same cluster. In the case of environmental criteria (C21, C22 and C23), certain contaminant transfer may occur between the 3 vectors corresponding to these criteria (water, air and soil). However, in this case the DM saw no influence among these criteria, iii) there is no influence among the three economic criteria (C11, C12 and C13). 


\begin{tabular}{|c|c|c|c|c|c|c|c|c|c|c|c|}
\hline & & \multicolumn{3}{|c|}{ Alternatives } & \multicolumn{3}{|c|}{ Economic criteria } & \multicolumn{3}{|c|}{$\begin{array}{c}\text { Environmental } \\
\text { criteria }\end{array}$} & \multirow{2}{*}{$\begin{array}{c}\begin{array}{c}\text { Social } \\
\text { crit. }\end{array} \\
\text { C31 }\end{array}$} \\
\hline & & $\begin{array}{c}\text { BAT } \\
1\end{array}$ & $\begin{array}{c}\text { BAT } \\
2\end{array}$ & $\begin{array}{c}\text { BAT } \\
3\end{array}$ & C11 & C12 & $\mathrm{C} 13$ & $\mathrm{C} 21$ & $\mathrm{C} 22$ & $\mathrm{C} 23$ & \\
\hline \multirow{3}{*}{ Alternatives } & BAT 1 & 0 & 0 & 0 & 1 & 1 & 1 & 1 & 1 & 1 & 1 \\
\hline & BAT 2 & 0 & 0 & 0 & 1 & 1 & 1 & 1 & 1 & 1 & 1 \\
\hline & BAT 3 & 0 & 0 & 0 & 1 & 1 & 1 & 1 & 1 & 1 & 1 \\
\hline \multirow{3}{*}{$\begin{array}{c}\text { Economic } \\
\text { criteria }\end{array}$} & C11 & 1 & 1 & 1 & 0 & 0 & 0 & 1 & 1 & 1 & 1 \\
\hline & C12 & 1 & 1 & 1 & 0 & 0 & 0 & 1 & 1 & 1 & 1 \\
\hline & C13 & 1 & 1 & 1 & 0 & 0 & 0 & 1 & 1 & 1 & 1 \\
\hline \multirow{3}{*}{$\begin{array}{c}\text { Environmental } \\
\text { criteria }\end{array}$} & $\mathrm{C} 21$ & 1 & 1 & 1 & 1 & 1 & 1 & 0 & 0 & 0 & 1 \\
\hline & $\mathrm{C} 22$ & 1 & 1 & 1 & 1 & 1 & 1 & 0 & 0 & 0 & 1 \\
\hline & C23 & 1 & 1 & 1 & 1 & 1 & 1 & 0 & 0 & 0 & 1 \\
\hline Social criteria & C31 & 1 & 1 & 1 & 1 & 1 & 1 & 1 & 1 & 1 & 0 \\
\hline
\end{tabular}

Table 3: Interfactorial dominance matrix for BAT assessment using ANP

4.2.2.2 Determination of element and cluster priorities. The next stage includes all the steps of the ANP model. The first step consists of assigning priorities to related elements in order to build the unweighted supermatrix. To this end, each element (criterion or alternative) is analyzed in terms of which of the other elements, which have influence on it and belong to a certain cluster, exerts a greater influence on it and to what extent. In this way, for each column of the unweighted supermatrix we can identify blocks corresponding to each of the clusters whose values form the eigenvector that represents the relative influence of the elements of each cluster on the element under consideration. Each eigenvector has been calculated from the corresponding pairwise comparison matrices.

Due to the fact that in the case study different elements from different clusters have influences on one element the unweighted matrix is non-stochastic by columns. Thus according to Saaty (2001), all clusters that exert any kind of influence upon each group have to be prioritized using the corresponding cluster pairwise comparison matrices. The value corresponding to the priority associated with a certain cluster weights the priorities of the elements of the cluster on which it acts (in the unweighted supermatrix), and the weighted supermatrix can be generated. Appendix B shows the unweighted and weighted supermatrices.

To this end, a questionnaire was designed as a multiple-choice test and organized into tables that grouped the questions relative to the pairwise comparison matrices. The consistency ratios of the judgment matrices were always lower than 0.1 . Tables 4 and 5 show an example of the questionnaire. 
upon C11 Implementation costs in the cluster Economic criteria

A: C21 Wastewater Management

B: C22 Air Emission management

\begin{tabular}{|l|l|l|l|l|}
\hline Which has the greatest influence? & $\square$ A & B B & $\square$ Equally important & \\
\hline To what extent? & \ Moderate & $\square$ Strong & $\square$ Very strong & $\square$ Extreme \\
\hline
\end{tabular}

Table 4: Example of the questionnaire about prioritization of elements

Compare the following groups that have some influence upon the cluster Environmental criteria

A: Alternatives

B: Economic criteria

\begin{tabular}{|l|l|l|l|l|}
\hline Which has the greatest influence? & \ A & $\square$ B & $\square$ Equally important & \\
\hline To what extent? & \ Moderate & $\square$ Strong & $\square$ Very strong & $\square$ Extreme \\
\hline
\end{tabular}

Table 5: Example of the questionnaire about prioritization of clusters

4.2.2.3 Calculation of the limit matrix and resulting prioritization. By raising the weighted supermatrix to successive powers the limit matrix is obtained. The results of the model are shown in Table 6, expressed as distributive mode

\begin{tabular}{l|l|}
\cline { 2 - 2 } & Priority \\
BAT 1 & 0.435 \\
BAT 2 & 0.119 \\
BAT 3 & 0.446 \\
\hline
\end{tabular}

Table 6: BAT Priorities according to the network approach

BAT 3 (use of pneumatic conveying systems) is the most appropriate BAT to reduce particulate emissions to the atmosphere in the installation of this case study with a priority of $44.6 \%$. On the other hand, the priority of BAT 1 (covering of the conveyor working with dusty materials) is $43.5 \%$, similar to that of BAT3

\subsection{Phase of evaluation of results}

Table 7 shows the results obtained with each decision model. In this case study, there are not noticeable differences between BAT prioritization in both decision analysis models, being BAT 3 slightly better than BAT 1.

\begin{tabular}{|l|l|l|l|l|}
\hline & AHP & RANKING & & ANP \\
\hline BAT 3 & 0.458 & 1 & BAT 3 & 0.446 \\
\hline BAT 1 & 0.430 & 2 & BAT 1 & 0.435 \\
\hline BAT 2 & 0.112 & 3 & BAT 2 & 0.119 \\
\hline
\end{tabular}

Table 7 BAT Priorities depending on the decision model used

If the criteria weights obtained in the hierarchy model are compared to the criteria influences obtained in the network model some differences can be observed (Table 8) 


\begin{tabular}{|l|c|l|l|}
\hline CRITERIA & AHP & ANP & CRITERIA \\
\hline C13. Energy efficiency & 0,400 & 0.223 & C11. Implementation costs \\
\hline C12. Resource consumption & 0,199 & 0.209 & C13. Energy efficiency \\
\hline C11. Implementation costs & 0,143 & 0.148 & C22. Air emissions management \\
\hline C31. Workers health & 0,074 & 0.133 & C12. Resource consumption \\
\hline C22. Air emissions management & 0,072 & 0.128 & C31. Workers health \\
\hline C21. Waste water management & 0,059 & 0.086 & C21. Wastewater management \\
\hline C23. Waste management & 0,054 & 0.072 & C23. Waste management \\
\hline
\end{tabular}

Table 8 Comparison of the priorities of the criteria depending on the decision model used

In the hierarchy model the most important criteria are the economic criteria, while in the ANP model criterion C22 (Air Emissions Management) gains substantial influence. This is logical because they are evaluating BAT for the reduction of particulate emissions to the atmosphere. According to the DM, these results seem more logical than those initially obtained with the hierarchy model.

Table 9 shows the weights / influences of the higher-level criteria (clusters). One can see that in the AHP model the DM gives great importance to the economic criteria, while in the network model this cluster loses influence in favor of the other two clusters. This is in agreement with the principles of sustainable development, whereby the three clusters should tend to have a similar importance

\begin{tabular}{|l|l|l|l|}
\hline CLUSTERS & AHP & ANP & CLUSTERS \\
\hline ECONOMIC CRITERIA & 0.741 & 0.565 & ECONOMIC CRITERIA \\
\hline ENVIRONMENTAL CRITERIA & 0.184 & 0.307 & ENVIRONMENTAL CRITERIA \\
\hline SOCIAL CRITERIA & 0.074 & 0.128 & SOCIAL CRITERIA \\
\hline
\end{tabular}

Table 9 Comparison of the priorities of the clusters depending on the decision model used

Table 10 shows a comparison of the number of individual judgments in the hierarchy and network models. It also indicates which judgments should include IPPC considerations. The conclusions drawn from the table are:

- For an assessment of three BAT with seven evaluation criteria, each member of the DM has to give 45 judgments (pairwise comparisons) more in the ANP model than in the AHP model (75 versus 30 comparisons). Consequently ANP requires greater efforts from the DM.

- The implementation of the IPPC approach is more effective in the evaluation of BAT by ANP, as the analysis of BAT influences on the criteria is only possible using this method. 


\begin{tabular}{c|cc}
\hline Comparison of clusters & AHP & ANP \\
$\begin{array}{c}\text { Comparison of } \\
\text { evaluation criteria }\end{array}$ & $\begin{array}{c}2 \times 3=6 \\
\text { comparisons }\end{array}$ & $\begin{array}{c}3 \times 4=12 \text { comparisons } \\
\text { comparison of BAT } \\
\text { with respect to }\end{array}$ \\
$\begin{array}{c}\text { evaluation criteria } \\
\text { Comparison of } \\
\text { evaluation criteria with } \\
\text { respect to BAT }\end{array}$ & $\begin{array}{c}3 \times 7=21 \\
\text { comparisons }\end{array}$ & $\begin{array}{c}3 \times 7=21 \\
\text { comparisons }\end{array}$ \\
& - & $3 \times 6=18$ comparisons \\
\end{tabular}

Table 10: Number and type of individual judgments for the evaluation of three BAT in AHP and ANP

\subsection{Sensitivity analysis}

Judgments in any decision-making problem are surrounded by imprecision, so that results can be modified. It is therefore useful to perform a sensitivity analysis to analyze how the results are influenced by possible changes in some elements of the decision problem.

In the hierarchical model, this analysis is relatively simple to do. The weights on each of the criteria can be changed within a range of variation, by keeping the weight proportion of the others and observing the results. The influences of some alternatives over certain criteria can also be changed, if it is thought there may be imprecision in these assessments.

Figure 4 shows the change produced in the AHP alternative priorities when the weight of the criterion $\mathrm{C} 13$ Energy efficiency is modified within a range of $\pm 25 \%$. We can observe that, when the weight of this criterion is increased in $25 \%$ (from 0,4 to 0,5 ), the alternative BAT3 reaches the same priority as BAT1 The same process has been made for the rest of criteria and no significant changes have been observed.

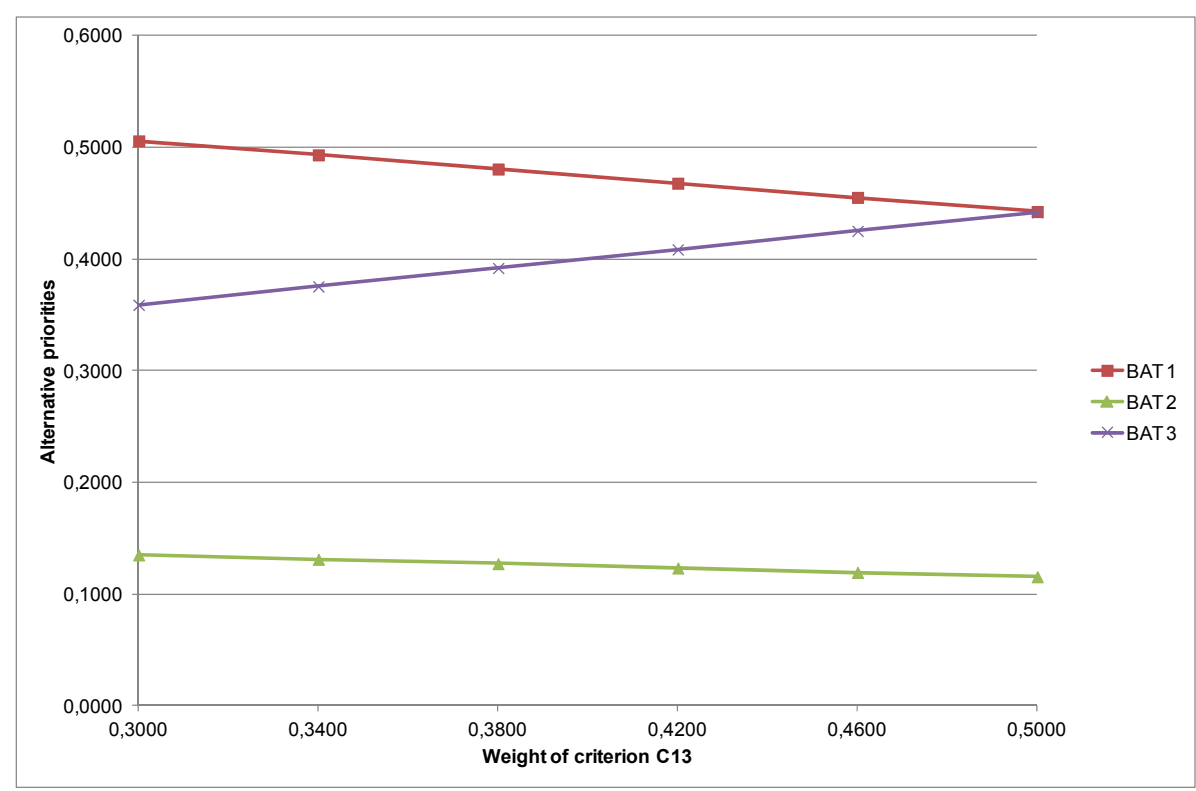

Figure 4. Sensitivity analysis hierarchy model. Criterion C13 
In the network model, the analysis is more complex to perform. Possible solutions are: to consider those values of the weighted matrix that arose in the discussion between the DM team members; discuss possible changes to certain values in the array of clusters, or remove certain influences among elements in the model. To illustrate this analysis, Figure 5 shows the evolution of ANP alternative priorities when the influence of Criterion $\mathrm{C} 11$ Implementation Costs over BAT1 is modified within a range of $20 \%$

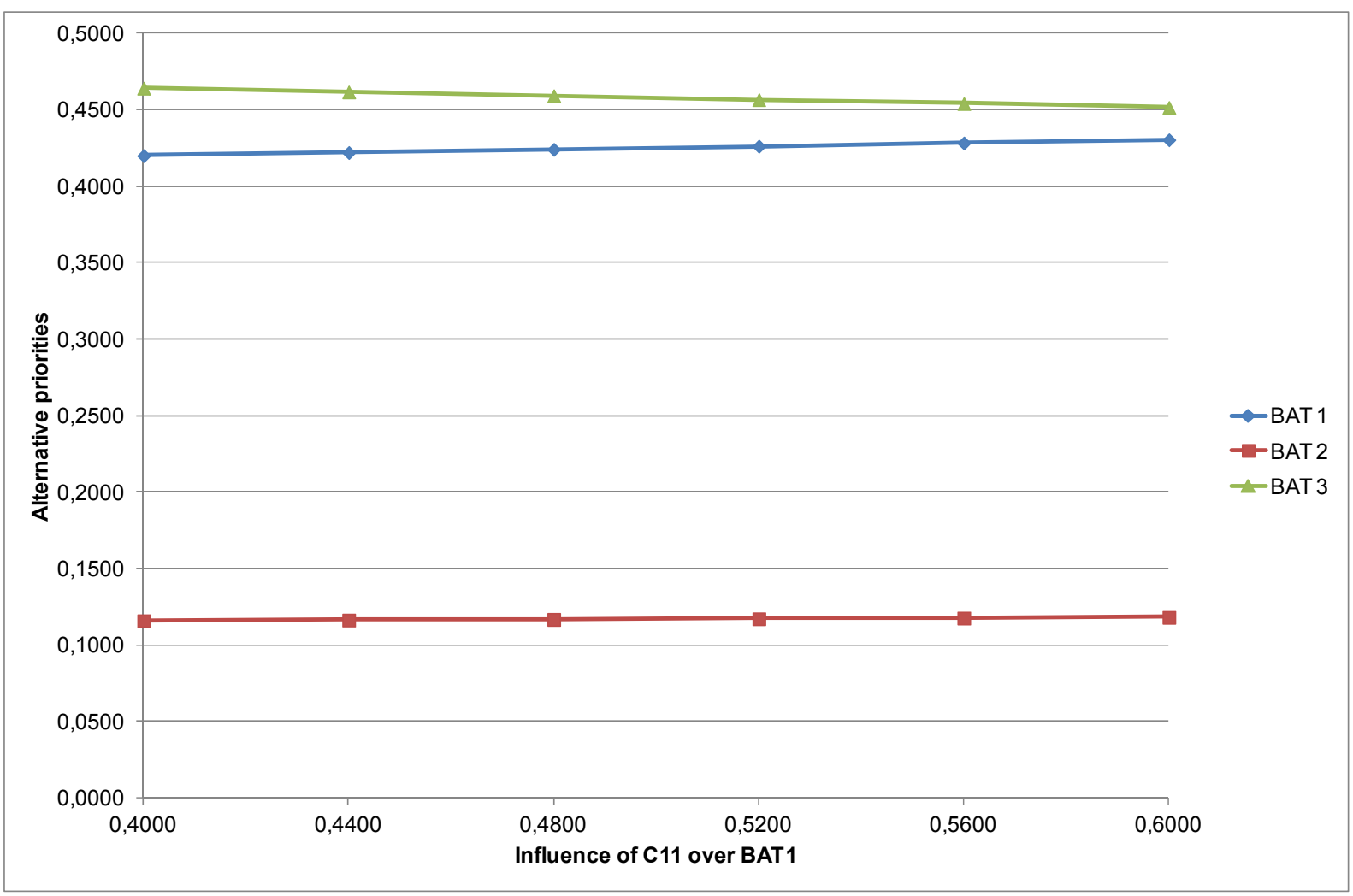

Figure 5. Sensitivity analysis network model. Influence of Criterion C11 over BAT1

\section{CONCLUSIONS}

This paper presents a new approach for the evaluation of BAT based on two multicriteria decision models, AHP and ANP. The selection of the best BAT to improve environmental impact of an industry is a decision to be made by the competent environmental authority, who must evaluate different BAT included in the reference documents. The IPPC Directive does not specify any assessment method. This paper describes a robust and scientific method for a better implementation of the IPPC approach

The method has been applied to a case study of an Integrated Environmental Authorization granted to a ceramic industry of Castellón (Spain), which sets the limit value for particulate emissions to the atmosphere. The hierarchy model and the network model were used in the analysis. AHP was easier to use and understand by the DM. However, given that the assessment of BAT depends on the characteristics of the BAT and the IPPC installation and its environmental conditions, it becomes evident that there is some kind of influence among the different elements of the decision problem. Consequently, whenever possible, it is preferable to use the network model. 
The analysis of the results obtained allowed the DM to observe which criteria that initially were considered as very significant in the hierarchy model, in the network model did not exert such a great influence. This is because in the hierarchical model, the criteria are weighted regardless of what alternatives are considered. This fact allowed for a deep reflection on the process that was very useful in the analysis of results.

In order to reduce uncertainty and imprecision in the decision making process, it is useful to carry out a sensitivity analysis, which takes into account those aspects that have attracted the most discussion.

Although the case study presented in this paper is relatively simple, AHP and ANP are designed to make complex decisions that may contain a high number of criteria and alternatives. Environmental problems are characterized by having to analyze many factors and in many cases, numerous alternatives. The human mind has trouble managing more than $7 \pm 2$ concepts simultaneously. Therefore, the analysis of such problems through hierarchical or network models, allows breaking it down into parts, gathering it into small groups and focusing the mind of the DM in making comparisons of the elements in pairs. The comparison matrices are not excessively large and this allows the DM to manage all the information well. Although the DM has to answer numerous questions (especially ANP) all of them are very simple to answer, as shown in Tables 4 and 5 .

Another advantage of AHP / ANP is that an ex-post analysis of results of the decision making process can be made, so the decision-making process is traceable, an issue that is highly valued by the DM. 


\section{Appendices}

Appendix A. Pairwise comparison matrices. Hierarchy model

\begin{tabular}{c|cccc|}
\hline & Economic criteria & Environmental criteria & Social criteria & Priority \\
Economic criteria & 1 & 5.11 & 7.88 & 0.741 \\
Environmental criteria & 0.19 & 1 & 3.17 & 0.184 \\
Social criteria & 0.13 & 0.31 & 1 & 0.074 \\
\cline { 2 - 5 }
\end{tabular}

Table A.1 Judgment aggregation matrix for higher-level criteria

\begin{tabular}{c|cccc|}
\hline & C11 & C12 & C13 & Priorities \\
C11 & 1 & 0.62 & 0.41 & 0.193 \\
C12 & 1.60 & 1 & 0.43 & 0.268 \\
C13 & 2.41 & 2.34 & 1 & 0.540 \\
\hline
\end{tabular}

Table A.2 Judgment aggregation matrix for the economic criteria

\begin{tabular}{l|cccc|}
\hline & C21 & C22 & C23 & Priorities \\
C21 & 1 & 0.75 & 1.18 & 0.318 \\
C22 & 1.32 & 1 & 1.25 & 0.391 \\
C23 & 0.85 & 0.80 & 1 & 0.291
\end{tabular}

Table A.3 Judgment aggregation matrix for the environmental criteria 


\begin{tabular}{|c|c|c|c|c|c|c|c|c|c|}
\hline & \multicolumn{3}{|c|}{ C11 } & \multicolumn{3}{|c|}{$\mathrm{C} 12$} & \multicolumn{3}{|c|}{ C13 } \\
\hline & BAT 1 & BAT 2 & BAT 3 & BAT 1 & BAT 2 & BAT 3 & BAT 1 & BAT 2 & BAT 3 \\
\hline BAT 1 & 1 & 4.05 & 7.76 & 1 & 3.62 & 6.19 & 1 & 6.80 & 0.32 \\
\hline BAT 2 & 0.25 & 1 & 1.90 & 0.28 & 1 & 1.71 & 0.16 & 1 & 0.11 \\
\hline \multirow[t]{3}{*}{ BAT 3} & 0.13 & 0.53 & 1 & 0.16 & 0.58 & 1 & 3.08 & 8.96 & 1 \\
\hline & \multicolumn{3}{|c|}{$\mathrm{C} 21$} & \multicolumn{3}{|c|}{$\mathrm{C} 22$} & \multicolumn{3}{|c|}{$\mathrm{C} 23$} \\
\hline & BAT 1 & BAT 2 & BAT 3 & BAT 1 & BAT 2 & BAT 3 & BAT 1 & BAT 2 & BAT 3 \\
\hline BAT 1 & 1 & 2.01 & 1.33 & 1 & 3.26 & 0.16 & 1 & 4.76 & 0.41 \\
\hline BAT 2 & 0.50 & 1 & 0.53 & 0.31 & 1 & 0.11 & 0.21 & 1 & 0.13 \\
\hline \multirow[t]{3}{*}{ BAT 3} & 0.75 & 1.89 & 1 & 6.14 & 8.66 & 1 & 2.45 & 7.69 & 1 \\
\hline & \multicolumn{3}{|c|}{ C31 } & & & & & & \\
\hline & BAT 1 & BAT 2 & BAT 3 & & & & & & \\
\hline BAT 1 & 1 & 3.95 & 0.47 & & & & & & \\
\hline BAT 2 & 0.25 & 1 & 0.12 & & & & & & \\
\hline BAT 3 & 2.13 & 8.46 & 1 & & & & & & \\
\hline
\end{tabular}

Table A.4: BAT priority matrices with respect to the evaluation criteria 
Appendix B. Pairwise comparison matrices. Network model

\begin{tabular}{|c|c|c|c|c|c|c|c|c|c|c|c|}
\hline & & \multicolumn{3}{|c|}{ Alternatives } & \multicolumn{3}{|c|}{ Economic criteria } & \multicolumn{3}{|c|}{$\begin{array}{c}\text { Environmental } \\
\text { criteria }\end{array}$} & \multirow{2}{*}{$\begin{array}{c}\begin{array}{c}\text { Social } \\
\text { criter. }\end{array} \\
\text { C31 }\end{array}$} \\
\hline & & $\begin{array}{c}\text { BAT } \\
1\end{array}$ & $\begin{array}{c}\text { BAT } \\
2\end{array}$ & $\begin{array}{c}\text { BAT } \\
3\end{array}$ & C11 & C12 & C13 & $\mathrm{C} 21$ & $\mathrm{C} 22$ & $\mathrm{C} 23$ & \\
\hline \multirow{3}{*}{ Alternatives } & BAT 1 & 0 & 0 & 0 & 0.73 & 0.70 & 0.28 & 0.44 & 0.17 & 0.30 & 0.30 \\
\hline & BAT 2 & 0 & 0 & 0 & 0.18 & 0.19 & 0.06 & 0.20 & 0.07 & 0.07 & 0.07 \\
\hline & BAT 3 & 0 & 0 & 0 & 0.09 & 0.11 & 0.66 & 0.36 & 0.77 & 0.63 & 0.63 \\
\hline \multirow{3}{*}{$\begin{array}{l}\text { Economic } \\
\text { criteria }\end{array}$} & $\mathrm{C} 11$ & 0.69 & 0.20 & 0.30 & 0 & 0 & 0 & 0.10 & 0.07 & 0.14 & 0.15 \\
\hline & $\mathrm{C} 12$ & 0.13 & 0.68 & 0.13 & 0 & 0 & 0 & 0.68 & 0.29 & 0.53 & 0.22 \\
\hline & $\mathrm{C} 13$ & 0.18 & 0.12 & 0.58 & 0 & 0 & 0 & 0.22 & 0.65 & 0.33 & 0.63 \\
\hline \multirow{3}{*}{$\begin{array}{l}\text { Environmental } \\
\text { criteria }\end{array}$} & $\mathrm{C} 21$ & 0.06 & 0.06 & 0.06 & 0.25 & 0.43 & 0.71 & 0 & 0 & 0 & 0.18 \\
\hline & $\mathrm{C} 22$ & 0.72 & 0.66 & 0.71 & 0.41 & 0.24 & 0.17 & 0 & 0 & 0 & 0.68 \\
\hline & $\mathrm{C} 23$ & 0.22 & 0.28 & 0.23 & 0.34 & 0.33 & 0.12 & 0 & 0 & 0 & 0.13 \\
\hline Social criteria & C31 & 1.00 & 1.00 & 1.00 & 1.00 & 1.00 & 1.00 & 1.00 & 1.00 & 1.00 & 0.00 \\
\hline
\end{tabular}

Table B.6: Unweighted supermatrix

\begin{tabular}{|c|c|c|c|c|c|c|c|c|c|c|c|}
\hline & & \multicolumn{3}{|c|}{ Alternatives } & \multicolumn{3}{|c|}{ Economic criteria } & \multicolumn{3}{|c|}{$\begin{array}{l}\text { Environmental } \\
\text { criteria }\end{array}$} & \multirow{2}{*}{$\begin{array}{c}\begin{array}{c}\text { Social } \\
\text { criter. }\end{array} \\
\text { C31 }\end{array}$} \\
\hline & & $\begin{array}{c}\text { BAT } \\
1\end{array}$ & $\begin{array}{c}\text { BAT } \\
2\end{array}$ & $\begin{array}{c}\text { BAT } \\
3\end{array}$ & C11 & C12 & C13 & $\mathrm{C} 21$ & $\mathrm{C} 22$ & $\mathrm{C} 23$ & \\
\hline \multirow{3}{*}{ Alternatives } & BAT 1 & 0 & 0 & 0 & 0.46 & 0.44 & 0.18 & 0.28 & 0.10 & 0.19 & 0.19 \\
\hline & BAT 2 & 0 & 0 & 0 & 0.11 & 0.12 & 0.03 & 0.13 & 0.04 & 0.04 & 0.05 \\
\hline & BAT 3 & 0 & 0 & 0 & 0.06 & 0.07 & 0.41 & 0.22 & 0.48 & 0.40 & 0.40 \\
\hline \multirow{3}{*}{$\begin{array}{l}\text { Economic } \\
\text { criteria }\end{array}$} & C11 & 0.51 & 0.15 & 0.22 & 0 & 0 & 0 & 0.03 & 0.02 & 0.04 & 0.02 \\
\hline & C12 & 0.10 & 0.50 & 0.09 & 0 & 0 & 0 & 0.19 & 0.08 & 0.15 & 0.02 \\
\hline & $\mathrm{C} 13$ & 0.13 & 0.09 & 0.43 & 0 & 0 & 0 & 0.06 & 0.18 & 0.09 & 0.07 \\
\hline \multirow{3}{*}{$\begin{array}{c}\text { Environmental } \\
\text { criteria }\end{array}$} & $\mathrm{C} 21$ & 0.01 & 0.01 & 0.01 & 0.07 & 0.12 & 0.20 & 0 & 0 & 0 & 0.05 \\
\hline & $\mathrm{C} 22$ & 0.13 & 0.12 & 0.13 & 0.11 & 0.07 & 0.05 & 0 & 0 & 0 & 0.18 \\
\hline & $\mathrm{C} 23$ & 0.04 & 0.05 & 0.04 & 0.10 & 0.09 & 0.03 & 0 & 0 & 0 & 0.03 \\
\hline Social criteria & C31 & 0.07 & 0.07 & 0.07 & 0.09 & 0.09 & 0.09 & 0.09 & 0.09 & 0.09 & 0.00 \\
\hline
\end{tabular}

Table B.7: Weighted supermatrix

\section{Acknowledgements}

The translation of this paper was funded by the Universitat Politècnica de València 


\section{References}

Aragonés-Beltrán, P., Pastor-Ferrando, J.P., García-García, F., 2010. An Analytic Network Process approach for siting a municipal solid waste plant in the Metropolitan Area of Valencia (Spain). Journal of Environmental Management, 91, 1071-1086.

Aragonés-Beltrán, P., Chaparro-González, F., Pastor-Ferrando, J.P., Rodríguez-Pozo, F., 2010b. An ANP-based approach for the selection of photovoltaic solar power plant investment projects. Renewable and Sustainable Energy Reviews, 14, 249-264.

Ashford, A. y Hall, R.P., 2011. Technology, Globalization and Sustainable Development. Yale University Press, New Haven, USA.

Ayag, Z., Ozdemir R.G., 2006. A fuzzy AHP approach to evaluating machine tool alternatives. Journal of Intelligent Manufacturing, 17, 179-190.

Barros, M.C., Magán, A., Valiño, S., Bello, P.M., Casares, J.J., Blanco, J.M., 2008. Identification of best available techniques in the seafood industry: a case study. Journal of Cleaner Production, 17, 391-399.

Belton, V., Stewart. T., 2002. Multiple criteria decision analysis. An integrated approach, second ed. Kluwer Academic Publishers, Dordrecht, Netherlands.

Bollinger, D., Pictet, J., 2008. Multiple criteria decision analysis of treatment and land-filling technologies for waste incineration residues. OMEGA The International Journal of Management Science, 36, 418-428.

Bréchet, T., Tulkens, H., 2009. Beyond BAT: selecting optimal combinations of available techniques, with an example from the limestone industry. Journal of Environmental Management, 90, 1790-1801.

Chan, F.T.S., Ip, R.W.L., Lau, H., 2001. Integration of expert system with analytic hierarchy process for the design of material handling equipment selection system. Journal of Materials Processing Technology, 116, 137-145.

European Comission, 2010. Europe 2020. A strategy for smart, sustainable and inclusive growth. $\operatorname{COM}(2010) 2020$ final.

Chowdhury, S., Husain, T., 2006. Evaluation of drinking water treatment technology: an entropy-based fuzzy application. Journal of Environmental Engineering, 132, 1264-1271.

Cziner, K., Tuomaala, M., Hurme, M., 2005. Multicriteria decision making in process integration. Journal of Cleaner Production, 13, 475-483.

Du, Y., Cao, H., Liu, F., Li, C., Chen, X., 2012. An integrated method for evaluating the remanufacturability of used machine tool. Journal of Cleaner Production, 20, 82-91.

Dağdeviren, M., Eraslan, E., 2008. Priority determination of strategic energy policies in Turkey using Analytic Network Process (ANP) with group decision making. International Journal of Energy Research, 32, 1047-1057.

Doukas H., Patlitzianas, K.D., Psarras, J., 2006. Supporting sustainable electricity technologies in Greece using MCDM. Resources Policy, 31, 129-136.

Dijkmans, R., 2000. Methodology for selection of best available techniques (BAT) al the sector level. Journal of Cleaner Production, 8, 11-21.

Erdoğmuş, Ş., Aras, H., Koç, E., 2006. Evaluation of alternative fuels for residential heating in Turkey using analytical network process (ANP) with group decision-making. Renewable \& Sustainable Energy Reviews, 10, 269-279. 
European Parliament, 2008. Directive 2008/1/EC of the European Parliament and of the Council, of 15 January 2008, concerning integrated pollution prevention and control (codified version). Official Journal of the European Union, L 24/8-29.

European Parliament, 2010. Directive 2010/75/UE of the European Parliament and of the Council, of 24 November 2010, on industrial emissions (integrated pollution prevention and control) (recast). Official Journal of the European Union, L 334/17-119.

Figueira, J., Greco, S., Ehrgott, M. (eds.), 2005. Multiple criteria decision analysis: State of the art surveys. Springer, New York, USA.

Geldermann, J., Rentz, O., 2001. Integrated technique assessment with imprecise information as a support for the determination of best available techniques (BAT). OR Spektrum, 23, 137-157.

Geldermann, J. Rentz, O., 2004. The reference installation approach for the technoeconomic assessment of emission abatement options and the determination of BAT according the IPPC-directive. Journal of Cleaner Production, 12, 389-402.

Georgopoulou, E., Hontou, V., Gakis, N., Sarafidis, Y., Mirasgedis, S., Lalas, D.P., Loukatos, A., Gargoulas, N., Mentzis, A., Economidis, D., Triantafilopoulos, T., Korizi, K., 2008. BEAsT: a decision-support tool for assessing the environmental benefits and the economic attractiveness of best available techniques in industry. Journal of Cleaner Production, 16, 359-373.

Gerdsri, N., Kocaoglu, D.F., 2007. Applying the analytic hierarchy process (AHP) to build a strategic framework for technology road mapping. Mathematical and Computer Modelling 46 (7-8), 1071-1080.

Gómez-López, M.D., Bayo, J., García-Cascales, M.S., Angosto, J.M., 2009. Decision support in disinfection technologies for treated wastewater reuse. Journal of Cleaner Production, 17, 1504-1511.

Gómez-Navarro, T., García-Melón, M., Acuña-Dutra, S., Díaz-Martín, D., 2009. An environmental pressure index proposal for urban development planning based on the analytic network process. Environmental Impact Assessment Review, 29, 319-329.

Honkasalo, N., Rodhe, H., Dalhammar, C., 2005. Environmental permitting as a driver for eco-efficiency in the dairy sector: a closer look at the IPPC Directive. Journal of Cleaner Production, 13, 1049-1060.

Instituto de Tecnología Cerámica y Comisión de Trabajo, 2009. BAT Guidelines for the manufacturing sector of ceramic tiles in Valencia region (in Spanish). Ed. Centro de Tecnologías Limpias. Conselleria de Medi Ambient, Aigua, Urbanisme i Habitatge. Generalitat Valenciana. Valencia, Spain. ISBN 978-84-482-5099-9. Available at: http://www.cma.gva.es/ctl

Jänicke, M., 2010. Innovations for a sustainable use of resources: reflections and proposals (In Spanish). Ekonomiaz, n 75, 70-83.

Jiang, Z., Zhang, H., Sutherland, J.W., 2011. Development of multi-criteria decision making model for remanufacturing technology portfolio selection. Journal of Cleaner Production, 19, 1939-1945.

Köne, A.Ç., Büke, T., 2007. An Analytical Network Process (ANP) evaluation of alternative fuels for electricity generation in Turkey. Energy Policy, 35, 5220-5228.

Liu, X., Wen, Z., 2012. Best available techniques and pollution control: a case study on China's thermal power industry. Journal of Cleaner Production, 23, 113-121. 
Pomerol, J.C., Barba-Romero, S., 2000. Multicriterion decision in management: Principles and practice. Kluwer Academic Publishers, Dordrecht, Netherlands.

Prabhu, T.R., Vizayakumar, K., 1996. Fuzzy hierarchical decision making (FHDM): a methodology for technology choice. International Journal of Computer Applications in Technology 9 (5-6), 322-329.

Saaty, TL., 1980. The Analytic Hierarchy Process. Mc Graw-Hill, New York, USA.

Saaty, TL., 1994. Fundamentals of decision making and priority theory with the AHP. RWS Publications, Pittsburgh, USA.

Saaty, T.L., 1996a. The Analytic Network Process: Decision making with dependence and feedback. RWS Publications, Pittsburgh, USA.

Saaty, TL., 1996b. The analytic hierarchy process: planning, priority setting, resource allocation. RWS Publications, Pittsburgh, USA.

Saaty, TL., 2001. Decision making with independence and feedback: The Analytic Network Process. RWS Publications, Pittsburgh, USA.

Saaty, TL., 2005. Theory and applications of the Analytic Network Process: decision making with benefits, opportunities, costs and risks. RWS Publications, Pittsburgh, USA.

Saaty, TL., 2008. Relative measurement and its generalization in decision making. Why pairwise comparisons are central in Mathematics for the measurement of intangible factors. The Analytic Hierarchy/Network Process. Revista de la Real Academia de Ciencias Exactas, Físicas y Matemáticas (RACSAM). 102 (2), 183-191.

Saaty, TL., Shang, J. 2011. An innovative orders-of-magnitude approach to AHP-based mutli-criteria decision making: Prioritizing divergent intangible humane acts. European Journal of Operational Research, 214(3), 703-715.

Saaty, TL, Peniwaty, K, 2008, Group Decision Making: Drawing out and Reconciling Differences. RWS Publications, Pittsburgh, USA.

Samarakoon, S.M.S.M.K., Gudmestad, O.T., 2011. The IPPC Directive and technique qualification at offshore oil and gas installations. Journal of Cleaner Production, 19, 13-20.

Schoenberger, H., 2009. Integrated pollution prevention and control in large industrial installations on the basis of best available techniques - The Sevilla Process. Journal of Cleaner Production, 17, 1526-1529.

Schultmann, F., Jochum, R., Rentz, O., 2001. A methodological approach for the economic assessment of best available techniques. LCA Methodology, 6(1), 19-27.

Subramoniam, R., Huisingh, D., Chinam,R.B., Subramoniam, S., 2011. Remanufacturing Decision-Making Framework (RDMF): research validation using the analytical hierarchical process. Journal of Cleaner Production (In Press), doi:10.1016/j.jclepro.2011.09.004.

Tabucanon, M.T., Batanov, D.N., Verman, D.K., 1994. Intelligent decision support system (DSS) for the selection process of alternative machines for flexible manufacturing systems (FMS). Computer in Industry, 25, 131-143.

Ulutas, B.H., 2005. Determination of the appropriate energy policy for Turkey. Energy, 30, 1146-1161.

Yüksel, I., Dağdeviren, M., 2007. Using the analytic network process (ANP) in a SWOT analysis-A case study for a textile firm. Information Sciences, 177, 3364-3382. 